\title{
The Relative Richness of the Poor? Natural Resources, Human Capital and Economic Growth*
}

\author{
Claudio Bravo-Ortega ${ }^{\dagger}$ \\ World Bank \\ and \\ Department of Economics \\ Universidad de Chile
}

\author{
José De Gregorio \\ Banco Central de Chile
}

Comments welcome

\begin{abstract}
Are natural resources a blessing or a curse? In this paper we present a model in which natural resources have a positive effect on level of income and a negative effect on its growth rate. The positive and permanent effect on income implies a welfare gain. There is a growth effect stemming from a composition effect. However, we show that this effect can be offset by having a large level of human capital. We test our model using panel data for the period 1970-1990. We extend the usual specifications for economic growth regressions by incorporating an interaction term between human capital and natural resources, showing that high levels of human capital may outweigh the negative effects of the natural resource abundance on growth. We also review the historical experience of Scandinavian countries, which in contrast to Latin America, another region well endowed with natural resources, shows how it is possible to grow fast based on natural resources.
\end{abstract}

JEL Classification: J24, O41, O57, Q00.

\footnotetext{
*We would to thank specially to Maurice Obstfeld for his comments that helped greatly improve our empirical work. We also would like to thank Pranab Bardhan, A. De Michaelis, Julian di Giovanni, Andrés Gómez-Lobo, Botond Kőszegi, Patricio Meller, Ted Miguel, David Romer, J.P. Stijns and the participants of the Seminars at the Universidad de Chile, University of California at Berkeley, and at the World Bank and Central Bank of Chile joint conference on Natural Resources and Growth for their helpful comments. Claudio Bravo-Ortega would also like to thank CIEPLAN and the Ministry of the Economy for their support and hospitality at different stages of this research.

$\dagger$ Address: The World Bank, MSN I-8-801 1818 H Street, N.W. Washington, DC 20433. E-mail: cbravoortega@worldbank.org

${ }^{\ddagger}$ E-mail:jdegrego@bcentral.cl
} 


\section{Introduction}

During the last decade many economists have returned to the familiar question of whether there is any relationship between a country's abundance of natural resources and its rate of economic growth or level of income. Few, however, have asked under what circumstances natural resources can serve as an engine of growth. Moreover, the discussion has been limited to the study of the effects on growth only, instead of looking also at the level of income, even though the latter is more closely related to welfare. In this paper we analyze both effects. We show that the discovery of natural resources leads to a decline in the rate of growth, but also to an increase in income that raises welfare.

The economic history of the last two centuries shows mixed evidence in this regard. During the nineteenth century and the first half of the twentieth century, several countries underwent development experiences in which natural resources seem to have been the engine of economic growth. The most notable cases include Australia, Scandinavia and the United States ( See Wright, 1990 and Blomstrom and Meller, 1990, among others). However, it is hard to find successful experiences of such development in the second half of the twentieth century. Indeed, in many countries the natural resources sector has been blamed for the underdevelopment or slow growth of the economy. This lack of variation in experiences, of course, limits our ability to use these more recent data to analyze the whole potential variety of actual experience with natural resources and development.

The mainstream literature on economic growth has focused on technical change and on the accumulation of physical and human capital, largely disregarding the interaction between these two factors within different economic structures. The main exception has been the research on the effects of openness on economic growth (Edwards, 1997). This situation has generated a conceptual gap in our understanding of the impact of the productive structure on economic growth.

During the 1970s many economists studied the macroeconomic effects and changes in the productive structure resulting from a shock to the natural resources sectorthe so-called Dutch disease. ${ }^{1}$ Nevertheless, this conceptual framework explains only the real appreciation of the currency and the process of factor reallocation that ac-

\footnotetext{
${ }^{1}$ On the literature on Dutch disease, see, for example, Neary and Van Wijnbergen (1986).
} 
companies it, without deriving long-run implications for economic growth. However, the idea behind the long-run effects of the Dutch disease is that the real appreciation that results from a natural resources boom is detrimental to export-led growth and development.

To understand the effects of Dutch disease on economic growth, it is necessary to identify the long-run mechanisms that link shocks to the natural resources sector with the country's productive structure and long-run performance. Matsuyama (1992), Sachs and Warner (1995), and more recently Asea and Lahiri (1999), among others, have attempted such an analysis. Yet the gap in our theoretical understanding remains wide. This paper tries to narrow that gap by developing a stylized model of two productive sectors, to consider both the dynamic effects of endogenous growth theory and the reallocative effects derived from the Dutch disease literature. We emphasize the interaction between natural resources and human capital, as well as their effects on levels of income and rates of economic growth, in order to explain why countries with an abundance of natural resources and with high levels of human capital may be able to reach a higher level of welfare. Moreover, we show that, under certain assumptions, a high level of human capital may offset the negative effects of an abundance of natural resources on economic growth. These facts are consistent with our discussion on the Scandinavian experience of development that we present in section 2, and that motivates our theoretical model.

One can distinguish two main reasons why the presence of natural resources might exert negative effects on growth and development. The first is that weak institutions generate conditions that give rise to "voracity effects," through which interest groups devote their energies to trying to capture the economic rents from natural resources (Lane and Tornell, 1996). The allocation of talent in such an economy is distorted, and resources are diverted to unproductive activities.

The second reason, which focuses on the productive structure of the economy, is related to the allocation of resources among different activities with different spillover effects on aggregate growth. For example, if a given stock of capital can be allocated either to the exploitation of natural resources or to the production of goods subject to endogenous growth, the presence of abundant natural resources may cause capital to be diverted to their extraction, thus diminishing the resources available for growthenhancing activities. We follow this second idea, but since, in a world with capital 
mobility, the constraint on a country's available physical capital stock may be relaxed, we focus on human capital, which is less mobile (Barro, Mankiw, and Sala-i-Martin, 1995). ${ }^{2}$

The model presented in section 3 incorporates the following stylized facts:

- According to Chenery and Syrquin (1975), the share of natural resources production in total output and the fraction of the labor force working in the natural resources sector both decline over the course of a country's development.

- An increase in a country's endowment of natural resources induces a shift in the fraction of human capital working in the industrial sector toward the natural resources sector, as has been traditionally understood in the study of Dutch disease.

The main results of our model derive from the fact that the rate of growth of an economy is a weighted average of the rate of growth of the natural resources sector and that of the industrial sector. The assumptions of our model imply that the natural resources sector uses a constant amount of human capital and does not grow, whereas the industrial sector can add human capital indefinitely and grow at a positive rate. Thus a larger endowment of natural resources increases income per capita but reduces the rate of growth of the economy by expanding the natural resources sector. A greater abundance of human capital generates faster growth for a given endowment of natural resources. In this regard we capture the idea that natural resources limit growth so long as the level of human capital is low, so that there are not enough resources to devote to growth-enhancing activities. We could also assume decreasing returns in the industrial sector by including physical capital, but that would make the model less tractable and deviate from the main effect we want to examine, namely, the role of human capital. In addition, we could presume that natural resources are also able to generate endogenous growth, for example by inducing spillovers to other activities through research and development, but we want to focus on the concept of a natural resources sector that, as the economy develops, reduces its share in total output.

\footnotetext{
${ }^{2}$ Even in periods of low capital mobility, foreign direct investment has traditionally been available to exploit natural resources.
} 
In Section 4 we analyze the empirical implications of the model, studying the effects of natural resources on GDP per capita and on its rate of growth. We find that, when interactions with human capital are ignored, an increased abundance of natural resources reduces the rate of growth but increases income. When we add to the regression analysis a term that interacts human capital and natural resources, we find that, for high levels of human capital, the rate of growth also increases with the abundance of natural resources. Section 5 concludes.

Scandinavia is perhaps the most striking case of development based on natural resources. For this reason, we motivated our theoretical model by presenting in the next section the experiences of Scandinavia and Latin America. As our review indicates, since the second half of the nineteenth century, a high level of human capital along with other factors made successful development possible for the first group of natural resources-rich countries. ${ }^{3}$

\section{Human Capital and Natural Resources: Scandinavia vs. Latin America}

A closer look at the history of Scandinavia and Latin America shows that, during the late nineteenth and early twentieth centuries, both groups of countries enjoyed similar levels of GDP per capita, and, more important from this paper's perspective, both were mostly exporters of natural resources. In 1870 Finland, Norway, and Sweden had incomes per capita of $\$ 1107, \$ 1303$ and $\$ 1664$, respectively, whereas Argentina and Chile had incomes per capita of $\$ 1311$ and $\$ 1153$, respectively. However, the long-run evolution of the two groups of countries was quite different: the Scandinavian countries developed, but the Latin American countries did not. By 1990 the divergence in income levels was striking. Whereas Finland, Norway, and Sweden by that year had incomes per capita of $\$ 16604$, $\$ 16897$ and $\$ 17695$, respectively, Argentina and Chile had fallen far behind, with incomes per capita of $\$ 6581$ and $\$ 6380$ dollars, respectively (table 1$){ }^{4}$

\footnotetext{
${ }^{3}$ See Leamer (2003) for more details on the relationship among distance, natural resources, and trade.

${ }^{4}$ All figures come from Maddison (1995).
} 
Table 1: Comparative evolution of Income and Exports Per Capita. (1990 Geary Khamis Dollars)

\begin{tabular}{||l|rrr|r|rrr|r||}
\hline & \multicolumn{3}{|c|}{ GDP per capita } & Growth & \multicolumn{3}{|c|}{ Exports } & Exports \\
& & & & GDP & \multicolumn{2}{|c}{ per capita } & Growth \\
& 1870 & 1913 & 1990 & $1870-1913$ & 1870 & 1913 & 1990 & $1870-1913$ \\
\hline Denmark & 1927 & 3764 & 17953 & 1.6 & 166 & 501 & 7642 & 3.3 \\
Finland & 1107 & 2050 & 16604 & 1.4 & 177 & 528 & 5222 & 3.9 \\
Netherlands & 2640 & 3950 & 16569 & 0.9 & 478 & 702 & 9346 & 2.3 \\
Norway & 1303 & 2275 & 16897 & 1.3 & 129 & 349 & 9145 & 3.2 \\
Sweden & 1664 & 3096 & 17695 & 1.5 & 171 & 475 & 6543 & 3.1 \\
UK & 3263 & 5032 & 16302 & 1.0 & 417 & 923 & 3363 & 2.8 \\
Australia & 3801 & 5505 & 16417 & 0.9 & 281 & 704 & 2732 & 4.8 \\
Canada & 1620 & 4213 & 19599 & 2.2 & 194 & 515 & 4934 & 4.1 \\
New Zealand & 3115 & 5178 & 13994 & 1.2 & 344 & 729 & & \\
USA & 2457 & 5307 & 21866 & 1.8 & 62 & 197 & 1765 & 2.2 \\
Argentina & 1311 & 3797 & 6581 & 2.5 & 124 & 257 & 372 & 5.2 \\
Brazil & 740 & 839 & 4812 & 0.3 & 87 & 80 & 235 & 1.9 \\
Chile & 1153 & 2653 & 6380 & 2.0 & 85 & 201 & 802 & 3.4 \\
Colombia & & 1236 & 4917 & & 48 & 51 & 242 & 2.0 \\
Mexico & 710 & 1467 & 4917 & 1.7 & 26 & 158 & 341 & 5.4 \\
Peru & 676 & 1037 & 3000 & 1.0 & 78 & 94 & 156 & 5.3 \\
\hline
\end{tabular}

Source: Maddison (1995) and Bravo-Ortega (1999). 
A variety of factors explain these differences in growth outcomes, and it is beyond the scope of this paper to analyze all of them. Instead we emphasize the most common factors identified in the literature, but we also stress the difference in their initial endowment of human capital, which has not been sufficiently appreciated despite the large differences on this score between the two regions (table 2 ). ${ }^{5}$

Table 2: Social Infrastructure Indicators 1870-1910

\begin{tabular}{|c|c|c|c|c|c|}
\hline & \multicolumn{2}{|c|}{$\begin{array}{l}\text { Railroad } \\
\text { (Km) }\end{array}$} & \multicolumn{2}{|c|}{$\begin{array}{c}\text { Primary } \\
\text { Enrollment }\end{array}$} & \multirow{2}{*}{$\begin{array}{r}\text { Literacy } \\
\text { Rate } \\
1870-90 \\
\end{array}$} \\
\hline & 1870 & 1910 & 1870 & 1910 & \\
\hline Denmark & 770 & 3445 & 58.3 & 65.8 & 99 \\
\hline Finland & 483 & 3356 & & 26.4 & 89 \\
\hline Netherlands & 1419 & 3190 & 59.1 & 70.3 & 97 \\
\hline Norway & 359 & 2976 & 60.8 & 68.6 & 98 \\
\hline Sweden & 1727 & 13829 & 56.9 & 66.9 & 98 \\
\hline UK & 21558 & 32184 & 48.7 & 78.5 & 96 \\
\hline Australia & & & 69.6 & 89.2 & 97 \\
\hline Canada & 4211 & 39799 & 75 & 88.2 & 90 \\
\hline New Zealand & & & 50 & 90.9 & \\
\hline USA & 85170 & 386714 & 72 & 97 & 88 \\
\hline Argentina & 732 & 27713 & 20.9 & 37 & 46 \\
\hline Brazil & 745 & 21326 & 5.8 & 10.8 & 14.8 \\
\hline Chile & 732 & 5944 & 18.7 & 38.8 & 30.3 \\
\hline Colombia & 0 & 988 & 5.9 & 20.8 & \\
\hline Mexico & 349 & 19748 & 16 & 24.8 & 22.2 \\
\hline Peru & 669 & 2995 & & 15.3 & \\
\hline
\end{tabular}

Source: Railroad from Mitchell (1998a and b). Enrollment rates from Benavot and Riddle (1988). Literacy from O'Rourke and Williamson (1995), except Brazil, Chile, and Mexico whose rates were taken from Engerman, Mariscal, and Sokoloff (1997). The figures for Brazil and Chile correspond to 1890, and those for Mexico to 1900.

Many have argued that the reason for the success of the Scandinavian transformation lies in how open these economies were. O'Rourke and Williamson (1995) establish that most of Sweden's catch-up was due to mass migration, international

\footnotetext{
${ }^{5}$ More recently, Maloney (2002) has studied in more detail this and other issues related to the capacity of resource-rich economies to absorb and develop technology.
} 
capital flows, and trade, and that this experience seems to apply to the rest of Scandinavia as well. This explanation assigns only modest importance to the relatively high level of educational attainment in the Scandinavian countries.

Nevertheless, what has not been widely recognized in the literature is that the Scandinavian countries were not the only resource-rich countries to experience high rates of economic growth during the late nineteenth century - the so-called Scandinavian catch-up. Some Latin American countries did so as well. Argentina and Chile experienced rapid growth, which by the late 1920s had raised their incomes per capita to levels above those in Finland, Italy, Norway, Portugal, and Spain. In these two Latin American countries, as in Scandinavia, international trade played a fundamental role. The openness of their economies and their comparative advantages - in beef and wheat for Argentina, and in nitrates for Chile - contributed to that growth. However, it is difficult to explain the greater persistence of growth in Scandinavia than in Latin America without remarking on the educational gap that emerged between the two groups of countries over the period 1870-1910, and which remained large throughout the twentieth century (table 2).

Bravo-Ortega (1999) argues that, despite some common characteristics, both groups of countries differed sharply in terms of income inequality, access to education, trade policies, and geographical location. By the beginning of the nineteenth century, the Scandinavian countries had implemented land redistributions and educational reforms. No similar transformations occurred in Latin America during that time. With regard to trade policies, whereas the Scandinavian countries, until 1900, tended consistently toward free trade, most Latin American governments (except Argentina and Chile) relied on trade tariffs as their principal source of income. Thus, by the late nineteenth century, both groups of countries had quite different structural conditions for accommodating the consequences of international trade.

This comparison of regional experiences confirms that education mattered in the nineteenth century. It was important in the development of new industrial activities in Scandinavia and in the economic and political accommodation of external shocks. A well-educated labor force facilitated the movement of workers across economic activities and assisted in sectoral restructuring as new industrial activities developed as part of the process of natural resource exploitation. Some examples of the benefits of this educational advantage are evident in studies of the changes in the industrial 
structure of the Scandinavian countries during the late nineteenth century. Examples include Denmark's shift from the export of grains to the export of livestock in the 1870's, the shift in Sweden and Norway from lumbering to pulp production, and Sweden's adoption and improvement of British metallurgical techniques, which allowed the Swedes to develop their iron and steel industries. ${ }^{6}$ An adjustment that in Latin America would have provoked a serious social crisis, as did the collapse of nitrates production in Chile, which led to a mass migration to the cities, proved instead for Scandinavia to be an episode of Schumpeterian creative destruction.

An alternative interpretation, based on an analysis of inequality and growth, is that access to primary education is simply a good proxy for reduced income inequality in Scandinavia. Increased equality would have contributed to a growing domestic market and would have furthered the development of new sectors.

Of course, there are many possible reasons why two regions that, more than a century ago, were similar in terms of income per capita and abundance of natural resources subsequently diverged, with very different patterns of development and economic growth. Clearly a salient difference, however, as the empirical analysis of this paper will show, was the level of human capital.

\section{The Model}

The model that we present follows from previous work on growth and natural resources starting with Solow (1974). Unlike Solow, however, we do not consider natural resources as an essential input for the production of industrial goods. ${ }^{7}$

We consider a small, open economy with two productive sectors: a natural resources sector and an industrial sector. Both utilize human capital along with the fixed endowments of the factors specific to each sector. We assume that the natural resources sector exhibits decreasing returns to human capital, whereas the industrial sector exhibits constant returns to scale. All production is sold in the international market, and the proceeds are used to buy a third, consumption good. The prices of the three goods are determined in the world market and therefore exogenous in the

\footnotetext{
${ }^{6}$ Heckscher (1968) notes that Sweden built the world's first industrial pulp processing plant, and covers the details of Swedish development of metallurgical techniques.

${ }^{7}$ More recently, Gylfason and Zoega (2002) also follow Solow's assumption about the essential role of natural resources in production.
} 
model. We use the price of the industrial good as a numeraire, and $p_{1}$ to denote the price of the natural resources good and $p_{2}$ the price of the consumption good.

Thus the production functions for the natural resources and industrial sectors can be expressed as follows:

$$
Y_{N R}=R \cdot H_{R}^{\delta} \quad \text { and } \quad Y_{I}=a \cdot H_{I}
$$

respectively.

We denote the capital specific to the natural resources sector by $R$. It represents a measure of the endowment of natural resources and its impact on output. Thus $R$ considers such factors as the quality of the soil, the climate, and the quality of mineral deposits. ${ }^{8}$

The capital specific to the industrial sector is denoted by $a$ and can be interpreted as technological (or social) infrastructure. As usual, the subscripts on $H$ (or $L$ ) indicate the productive sector to which the human capital (or labor) is allocated.

Hence the economy faces the following constraint for the endowment of human capital in each period:

$$
H_{I}+H_{R}=H
$$

To avoid scale effects, we work with just one representative firm for each sector, owned by a representative agent. We assume that the representative agent owns both firms. Total labor in the economy is constant and equal to $L$, which we normalize to 1 , and hence all variables are expressed in per capita terms. The proportion of labor and human capital allocated to the natural resources sector is equal to $L_{R}=H_{R} / H$, and that allocated to the industrial sector is $L_{I}=1-L_{R}=H_{I} / H$.

Thus the representative agent must choose the allocation of human labor across sectors and how much should be invested in human capital.

The agent solves the following problem:

\footnotetext{
${ }^{8}$ This assumption is similar to those used by Matsuyama (1992). Allowing for an optimal path of extraction for nonrenewable natural resources would imply, in our setup, a decreasing $\mathrm{R}$ over time and, hence, decreasing output in the natural resources sector. This result would reinforce some of the conclusions of our model, for example proposition 2.
} 


$$
\begin{gathered}
\operatorname{Max} \int_{0}^{\infty} \frac{c_{t}^{(1-\sigma)}-1}{(1-\sigma)} \cdot e^{-\beta t} d t \\
\text { st } \quad L \cdot \dot{H}_{t}=\dot{H}_{t}=Y-p_{2} \cdot c_{t} \\
Y=a \cdot\left(H_{I}\right)+p_{1} \cdot R \cdot H_{R}^{\delta} \\
H_{I}+H_{R}=H=L \cdot H .
\end{gathered}
$$

From this setup we derive the following five propositions, which are the basis of the empirical analysis presented in the next section. The first four propositions assume conditions for the existence of two productive sectors (assumption 1). Appendix A provides the solution of the model and the proofs of the propositions.

Assumption 1 The parameters of the model are such that in equilibrium both sectors have production greater than zero. This is equivalent to imposing, in period 0 ,

$H_{R}=H \cdot L_{R}=\left(\frac{a}{p_{1} \cdot R \cdot \delta}\right)^{\frac{1}{\delta-1}}<H_{0}$ and that $a>\beta$, where $H_{0}$ represents the endowment of human capital in the economy at period 0.

Proposition 1 In the steady state the growth rate of income per capita, consumption per capita, and human capital are equal to $\gamma_{s s}=\frac{1}{\sigma}(a-\beta)$

\section{Proof. See Appendix A.}

Note that, in the steady state, the rate of growth of the economy is constant and depends only on the technology used in the industrial sector and not on the endowment of natural resources. This is a direct consequence of the following proposition.

Proposition 2 In the steady state, the fraction of the labor force allocated to the natural resources sector converges asymptotically to zero. Output and human capital in the natural resource sector are constant.

\section{Proof. See Appendix A.}

Note that $L_{R}$, the fraction of the labor force working in the natural resources sector, can be expressed as

$$
L_{R}=\frac{1}{H}\left(\frac{p_{1} \cdot R \cdot \delta}{a}\right)^{\frac{1}{1-\delta}}
$$

The fraction of the labor force working in the natural resources sector is inversely proportional to the level of human capital per capita, $H$, and positively related to 
the amount of the specific factor in the natural resources sector. Hence, as long as human capital increases, the labor force in the natural resources sector decreases proportionately, and the level of human capital remains constant.

Now we turn to the effect of $R$ on the level of income.

Proposition 3 An increase in the specific factor in the natural resources sector results in an increase in income per capita.

\section{Proof. See Appendix A.}

The next proposition considers the growth effect of natural resources and the interplay with human capital. The proof redefines the variables in our system in order to arrive at a system of two nonlinear differential equations, which are then linearized around the steady state of the auxiliary dynamic system.

Result 1 The effect of an increase in the specific factor of the natural resources sector will be a lower growth rate of income per capita in the transition to the steady state. However, for economies with abundant human capital, the growth-reducing effects of an increase in the endowment of natural resources are diminished.

\section{Proof. See Appendix A.}

This result shows, first, that for low levels of human capital the growth effect of natural resources is negative, although the economy has higher income. A larger endowment in natural resources implies a larger share of total output in the natural resources sector. However, the greater the level of human capital, the smaller the crowding-out effect on the labor force of the industrial sector. The impact on growth can be understood by noting that the rate of growth is an average of the rates of growth in both sectors. Given that the natural resources sector has zero growth, the average declines whenever the natural resource share of total input increases. But when human capital is large, this composition effect is small. ${ }^{9}$

\footnotetext{
${ }^{9}$ Interestingly, Vincent (1997) notes that Malaysia's growth has behaved consistently with the assumptions and results of our model. Malaysia has three main regions: the peninsular mainland, Sabah, and Sarawak. Today peninsular Malaysia's economy is mostly based on manufactures, whereas the other two regions remain natural resources-based economies. Whereas in 1970 the primary sector accounted for 40 to 50 percent of output in all three regions, by 1990 it accounted just for 20 percent in the peninsular region and 60 percent in Sabah and Sarawak. Perhaps most interesting, whereas peninsular Malaysia's economy grew at an average annual rate of 3.8 percent during that period, those of Sabah and Sarawak grew at 2.9 and 3.4 percent, respectively.
} 
Figure 1: Growth Path.

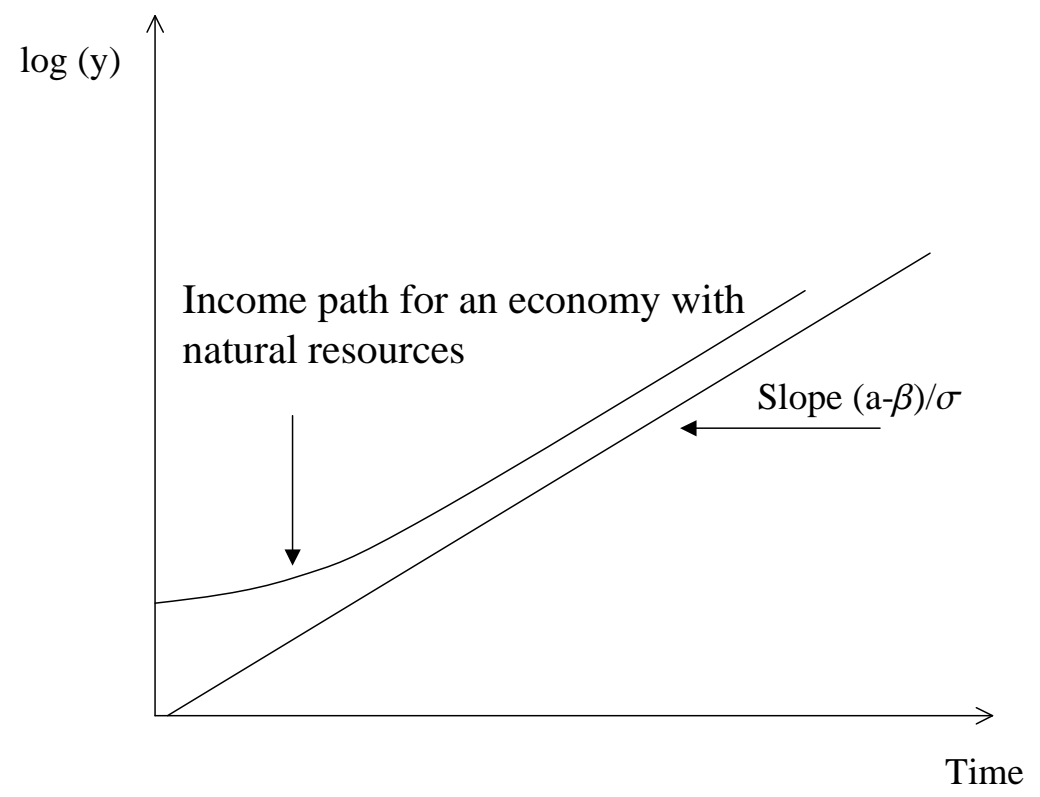

Figure 1 illustrates these effects. The economy converges with an increasing growth rate to the steady-state rate of growth. During this process the natural resources sector diminishes in relative importance. For two economies with the same level of human capital, the one with natural resources will have a higher income but will grow more slowly. But the economy with a higher level of human capital will be closer to the high steady-state rate of growth. For simplicity, and to illustrate these points more clearly, we have abstracted from the convergence effect, but the model can be interpreted as converging to a Solow-type growth based on the exogenous growth of productivity in the industrial sector, but with a dynamic similar to that 
described here.

Another interesting issue that this model allows us to explain is the existence of a zero-growth equilibrium in which the economy produces only in the natural resources sector. Assumption 1 ensures that the economy will never specialize entirely in natural resources. However, the next proposition analyzes what we call the "poverty trap of natural resources." In this case we assume that, given productivity in each of the two sectors and the initial level of human capital, the economy will produce only in the natural resources sector, because it is not profitable to devote resources to the industrial sector. This is formalized in the following assumption.

Assumption 2 The following inequalities hold:

$$
\begin{aligned}
& H_{R}=H \cdot L_{R}=\left(\frac{a}{p_{1} \cdot R \cdot \delta}\right)^{\frac{1}{\delta-1}}>H_{0} \\
& \beta>a
\end{aligned}
$$

Note that the first condition simply implies relative abundance of natural resources with respect to the specific factor in the industrial sector, whereas the second implies that the economy will exhaust the returns to human capital in the natural resources sector.

Proposition 4 Under the conditions of assumption 2, the economy will specialize in the production of the natural resources good, with zero growth of income per capita and zero rate of accumulation of human capital in the steady state.

\section{Proof. See Appendix A.}

So far we have proved that, under the proper assumptions, an increment in the specific factor in the natural resources sector will increase the level of income per capita, but will diminish the rate of growth in the economy. However, as shown in proposition 4 , it is possible to reduce this negative effect by increasing the level of human capital per capita. Hence the model presented here explains the stylized facts mentioned in the introduction. Moreover, as the latter proposition shows, the economy may become stagnant in a no-growth equilibrium, when it has a low level of human capital and low industrial productivity.

Finally, an extension of the model would allow us to incorporate the impact of political economy factors on the dynamics of the economy. Suppose that initially the 
economy produces in both sectors, and consider the existence of interest groups that receive the rents from at least one of the specific factors. Now suppose that these groups are able to tax the return on human capital. The impact of this tax will have three main consequences: First, it will reduce the return and the incentives for human capital accumulation, thereby reducing the growth rate of the economy over the transition and in the steady state. Second, the lower return to human capital will induce, ceteris paribus, a larger fraction of the labor force and a larger share of GDP to be allocated to the natural resources sector. Third, under some circumstances the tax would inhibit the development of the industrial sector, driving the economy into the "poverty trap" described by proposition 4. The same mechanisms operate when the owners of the natural resources sector are able to tax the return to the specific factor in the industrial sector. The tax charged to the specific factor will decrease its return and the productivity of human capital, which will ultimately imply a lower growth rate.

\section{Empirical Evidence}

\subsection{Previous Empirical Results}

Sachs and Warner, in a series of papers beginning with Sachs and Warner (1995), have produced the most persuasive evidence to date connecting economic growth and relative abundance of natural resources. Subsequent work includes Lane and Tornell (1996), Feenstra, Madani, Yang, and Liang (1997), Gylfason, Herbertsson, and Zoega (1999), Rodriguez and Sachs (1999), Sachs and Warner (1999, 2001), Asea and Lahiri (1999), and Gylfason (2001), among others. The main finding of Sachs and Warner (1995), using cross-sectional regressions, is a robust negative relationship between economic growth and natural resources. They corroborate this relationship with different measures of resource abundance, such as the share of mining production in GDP, land per capita, and the share of natural resource exports in GDP. ${ }^{10}$ Finally, Sachs and Warner find that a 1-standard-deviation increase in natural resources exports as a fraction of the GDP would imply a slower rate of growth on the order of

\footnotetext{
${ }^{10} \mathrm{It}$ is worth mentioning that the inclusion of natural resources exports (as a fraction of GDP) as an explanatory variable can be derived directly from the model we have developed. For more details see appendix A.
} 
1 percentage point per year.

Gylfason et al. (1999) postulate that the natural resources sector creates and needs less human capital than other productive sectors, which is similar to the assumption of this paper. A larger primary sector induces an appreciation of the currency, which makes the development of a skill-intensive sector difficult. Thus the model they develop predicts an inverse relationship between real exchange rate volatility and human capital accumulation and, hence, growth. Similarly, they predict a positive relationship between external debt and profitability in the secondary (industrial) sector and growth. However, the evidence they provide regarding these two explanatory variables is at best mixed: exchange rate volatility is not statistically significant, and external debt is statistically significant but has the wrong sign.

According to Gylfason et al. (1999), the share of the labor force in the primary sector can be used as an explanatory variable. However, they find it to be statistically significant only when human capital is excluded from the regressions. This result may be due to multicollinearity, which our model can explain, since the fraction of the labor force (or human capital) employed in the primary sector depends on the level of human capital. Thus Gylfason et al. (1999) find that "an increase in either the share of the primary sector in the labor force or in the share of the primary exports on total exports from $5 \%$ to $30 \%$ from one country or period to another reduces per capita growth by about $0.5 \%$ percent per year, other things being equal." In short, the model we have presented is consistent with the results found by Gylfason et al. (1999) related to the size of the labor force in the primary sector.

In a multisectoral study, Feenstra et al. (1997) test the hypothesis of semiendogenous growth using data on bilateral trade between the United States and South Korea and between the United States and Taiwan. Their study focuses on sixteen industrial sectors, for which they test whether changes in the relative varieties of inputs affect the growth rate of relative total factor productivity between South Korea and Taiwan. They classify seven of these sectors as primary and nine as secondary, defining firms that use raw materials and natural resources as inputs as belonging to the primary sector. Their results show that variety of inputs affects the growth rate of total factor productivity in seven secondary sectors but only one primary sector. The mining sector displays a positive relationship, although this effect disappears after controlling for imperfect competition. The remaining sectors in the primary sector 
present mixed evidence, with either a positive, a negative, or an insignificant effect of variety of inputs on the growth rate of total factor productivity.

However, not all the existing evidence supports the hypothesis of a negative impact of natural resources on economic development. Davis (1995) compares the longrun economic development indicators of minerals-based economies and non-mineralsbased developing economies. ${ }^{11}$ He finds that the minerals-based economies as a group significantly outperform the non-minerals-based economies. More recently, Rigobon and Manzano (2001) have found that Sachs and Warner's results are not robust to small changes in econometric procedure when panel data are used. They specifically analyze the impact on growth of natural resources exports as a share of GDP. They find that when the model is estimated on panel data using fixed effects, the negative impact of natural resources on growth vanishes, but that it remains in the cross-sectional estimations. Rigobon and Manzano argue that the high prices on commodities during the 1970s led developing countries to use them as collateral for debt. During the 1980s, commodity prices fell sharply, leaving developing countries with massive debts and a reduced flow of foreign resources with which to pay it back. Finally, Lederman and Maloney (2002) find that their preferred measure of natural resource abundance appears to be positively correlated with economic growth, and that export concentration reduces growth. They use as a measure of resource abundance the net exports of natural resources per worker.

\subsection{Empirical Methodology and Results}

We estimate the main empirical implications of our model using panel data for the period 1970-90. The data used in the regressions are from the Penn World Tables, the Barro and Lee (1994) Educational Data Set, and the World Tables from the World Bank (1993-96). We describe the data and their sources in more detail in appendix B.

We regress the growth rate of GDP per capita on various explanatory variables, using random and fixed effects to test the robustness of our measures of natural resources. $^{12}$ We also use instrumental variables in order to overcome the possible

\footnotetext{
${ }^{11}$ These indicators include life expectancy at birth, infant mortality, and share of the population with access to safe water and sanitation.

${ }^{12}$ Data limitations prevent estimation by some other procedures recommended in the literature,
} 
bias introduced by measurement error in our proxy for human capital. ${ }^{13}$. Given that we are interested in determining the possible effect of natural resource abundance on economic growth, we extend traditional growth regressions by incorporating the share of natural resources exports in GDP and in total exports as proxies of resource abundance (Natural). ${ }^{14}$ As control variables we use human capital, measured by average years of schooling among the over-25 population $(H)$; government expenditure as a fraction of GDP $(G)$; openness, measured as exports plus imports divided by GDP $(O P E N)$; terms-of-trade shocks $(T T){ }^{15}$ investment as a fraction of GDP $(I)$; and initial income $(y)$. All the variables are measured at the beginning of each period of the panel. However, as a robustness test, we also estimate regressions using average values of some variables for each period. All the estimations use either period dummies and regional dummies for Africa and Latin America, or fixed effects, depending on the estimation technique $(D R E G) .{ }^{16}$

Our benchmark regression for the rate of growth, $\gamma_{y}$, is the traditional growth equation extended by the inclusion of natural resources, as estimated by several authors and as implied by our model. ${ }^{17}$ This regression can be written as

$$
\begin{aligned}
\gamma_{y_{i, t}}=\alpha_{0 t}+\alpha_{1} \cdot y_{i, t} & +\alpha_{2} \cdot I_{i, t}+\alpha_{3} \cdot H_{i, t}+\alpha_{4} \cdot \text { Natural }_{i, t}+ \\
& +\alpha_{5} \cdot G_{i, t}+\alpha_{6} \cdot O P E N_{i, t}+\alpha_{7} \cdot T T_{i, t}+\alpha_{8} \cdot D R E G_{i}+\varepsilon_{i, t}
\end{aligned}
$$

where $i$ is a country index and $t$ indicates the number of the cross-section regression of the panel.

In a second stage we include an interaction effect between human capital and

such as the Generalized Method of Moments, as proposed by Caselli, Esquivel, and Lefort (1996).

${ }^{13}$ For a revision of this point see, for example, Krueger and Lindahl (1999).

${ }^{14} \mathrm{As}$ in most of the recent literature, we use the World Tables CD-ROM as a data source and define natural resources exports as the sum of exports of fuels and nonfuel primary products.

${ }^{15}$ We replicate the measure of terms-of-trade shock developed by Easterly, Pritchett, and Summers (1993). See appendix B.

${ }^{16}$ For a detailed discussion of the control variables see Sachs and Warner (1995) and Temple (1999). In our empirical specification we do not rule out the conditional convergence hypothesis; hence we include the lagged value of income per capita. Given the theoretical framework, it may be possible to recover conditional convergence to a given growth rate after including a decreasing marginal return to capital.

${ }^{17}$ Because in our model the economy exports all of its output, we can use either the share of natural resources exports in GDP or the share of natural resources exports in total exports as the proxy for resource abundance. See equation 30 
natural resources. Therefore we estimate the following regression:

$$
\begin{aligned}
\gamma_{y_{i, t}=\alpha_{0 t}+\alpha_{1} \cdot y_{i, t}} & \alpha_{2} \cdot I_{i, t}+\alpha_{3} \cdot H_{i, t}+\alpha_{4} \cdot \text { Natural }_{i, t}+ \\
& +\alpha_{5} \cdot G_{i, t}+\alpha_{6} \cdot O P E N_{i, t}+\alpha_{7} \cdot T T_{i, t}+ \\
& +\alpha_{8} \cdot H_{i, t} \cdot \text { Natural }_{i, t}+\alpha_{9} \text { DREG }_{i}+\varepsilon_{i, t}
\end{aligned}
$$

Equation (6) incorporates the interaction term between natural resources and human capital. This term allows us to test whether the negative effect of natural resources on the rate of growth decreases as human capital increases, as implied by our model. Hence we must interpret natural resources exports as a fraction of GDP and total exports as proxies of the specific factor in our model, $R$.

Before proceeding with the regression analysis, we show in figures 2 and 3 scatterplots of growth and income, respectively, against natural resource exports in our sample of countries. Figure 2 shows a negative relationship. In the case of income, there seems to be no bivariate relationship, although, as shown below, this relationship is positive when we control for other variables.

Table 3 presents results of regressions testing whether there is a negative relationship between natural resources and economic growth as modeled by equation (5); in these regressions we use instrumental variables in order to overcome the measurement error in our human capital variables, which Krueger and Lindahl (1999) have documented. We use as instruments the five-year-lagged value of our measure of human capital and the five-year-lagged value of government expenditure in education.

In Table 3, regression 3.1 shows the traditional result of Sachs and Warner for a panel estimation. However, regression 3.2 corroborates the results of Manzano and Rigobon (2002), who find that the significance of the share of natural resources exports in total GDP is not robust to the inclusion of fixed effects. Regression 3.3 instead uses the share of natural resources exports in total exports as a proxy for resource abundance. This variable turns out to be statistically and economically significant and robust to the inclusion of fixed effects, as shown in regression 3.4. Another variable that is not robust to the inclusion of fixed effects is government expenditure as a fraction of GDP. Regression 3.5 excludes this variable without altering the size and significance of the other explanatory variables, and without reducing the $R^{2}$. Human capital is significant at the $1 \%$ level in the random effects estimations, but only at 
the $10 \%$ level in the fixed effects estimations. Openness, investment, and the terms of trade are significant regardless of the estimation method. We also perform the Hausman test to determine whether the random effects or the fixed effects specification is more appropriate for each measure of natural resources. In both cases we reject the null hypothesis that there are no systematic differences in the coefficients estimated by the two methods.

Table 3: Determinants of Economic Growth (3.1-3.5). Instrumental Variables Estimations. Fixed (F.E.) and Random Effects (R.E.)

\begin{tabular}{||llllll||}
\hline & 3.1 & 3.2 & 3.3 & 3.4 & 3.5 \\
& Growth & Growth & Growth & Growth & Growth \\
& R.E. & F.E. & R.E. & F.E. & F.E \\
\hline $\log ($ Income $)$ & -0.023 & -0.092 & -0.027 & -0.090 & -0.090 \\
Openness & $(0.004)_{* * *}$ & $(0.013)_{* * *}$ & $(0.004)_{* * *}$ & $(0.012)_{* * *}$ & $(0.012)_{* * *}$ \\
& 0.019 & 0.043 & 0.008 & 0.043 & 0.043 \\
Investment & $(0.006)_{* * *}$ & $(0.017)_{* * *}$ & $(0.005)$ & $(0.015)_{* * *}$ & $(0.015)_{* * *}$ \\
& 0.063 & 0.105 & 0.064 & 0.088 & 0.088 \\
Government Exp. & $(0.027)_{* *}$ & $(0.044)_{* *}$ & $(0.027)_{* *}$ & $(0.043)_{* *}$ & $(0.043)_{* *}$ \\
& -0.100 & -0.024 & -0.106 & -0.012 & \\
Human & $(0.025)_{* * *}$ & $(0.048)$ & $(0.025)_{* * *}$ & $(0.047)$ & \\
Natural Resources $\left(\frac{X_{N R}}{Y}\right)($ & $(0.001)_{* * *}$ & 0.023 & 0.005 & 0.021 & 0.021 \\
& -0.057 & 0.026 & & & \\
Natural Resources II $\left(\frac{X_{N R}}{T X}\right)$ & $(0.016)_{* * *}$ & $(0.035)$ & & & \\
& & & -0.029 & -0.031 & -0.032 \\
Terms of Trade & & & $(0.007)_{* * *}$ & $(0.014)_{* *}$ & $(0.014)_{* *}$ \\
& 0.195 & 0.299 & 0.206 & 0.285 & 0.287 \\
R2 within & $(0.049)_{* * *}$ & $(0.063)_{* * *}$ & $(0.048)_{* * *}$ & $(0.060)_{* * *}$ & $(0.059)_{* * *}$ \\
Observations & 0.29 & 0.34 & 0.33 & 0.37 & 0.37 \\
& 326 & 326 & 326 & 326 & 326 \\
\hline
\end{tabular}

Standard errors in parentheses; $*$ significant at 10 percent ; $* *$ significant at 5 percent; *** significant at 1 percent. All the random effects regressions are estimated with regional dummies for African and Latin American countries.

Thus the results in Table 3 show an elasticity of the growth rate with respect to the relative abundance of natural resources (measured as a share of total exports) of around -0.03 . The estimations largely support the hypothesis that natural resources 
affect growth through their impact on the productive structure, even when the estimates control for investment, trade policy, fiscal policy, and shocks to the terms of trade.

Table 4 reports the results of regressions using the level of income per capita instead of the growth rate as the dependent variable, controlling for the same set of variables as before, with the obvious exception that the lagged value of income replaces that of the growth rate. Regressions 4.1 and 4.2 show that the share of natural resources exports in GDP is positively correlated with income. Whereas in the random effects estimation this variable is significant at the $1 \%$ level, in the fixed effects estimation it is significant only at the $10 \%$ level. Regressions 4.3 and 4.4 substitute the share of natural resources exports in total exports for the share in GDP as a regressor. In the random effects and fixed effects estimation this variable is insignificant at the $5 \%$ level, although it is still correlated positively with income.

Thus the empirical evidence in Tables 3 and 4 confirms two of the main predictions of the model: a positive effect of natural resource abundance on income per capita and a negative effect on the rate of growth. We note that it is the share of natural resources in GDP that is positively correlated with income, but it is the share of natural resources in total exports that is negatively correlated with the growth rate. These results may indicate that countries well endowed with natural resources enjoy greater welfare, as indicated by Davis (1995) and suggested by our model. The significance of natural resources exports in explaining the growth rate may fit the predictions of our model. However, it may also indicate that export concentration is damaging for growth, as suggested by Lederman and Maloney (2002).

We also estimated but do not report specifications in which we did not control for investment. The natural resources coefficient and its significance remained largely unchanged, which we interpret as indicating that the negative effect of natural resources on growth does not operate through the investment channel but rather through the relative productivity among sectors, and consequently through their relative sizes. ${ }^{18}$

Table 5 shows the effect of the interaction between natural resources and human capital using instrumental variables. In regression 5.1 neither the interaction term

\footnotetext{
${ }^{18}$ Gylfason et al. (1999) consistently find that the share of the labor force employed in the primary sector (farming, forestry, hunting, and fishing) adversely affects the rate of growth. Indeed, they found this variable to be more robust than the measures of human capital they utilized.
} 
Table 4: Determinants of Level of Income. Instrumental Variables estimations. Fixed (F.E.) and Random Effects (R.E.)

\begin{tabular}{||lllll||}
\hline & 4.1 & 4.2 & 4.3 & 4.4 \\
& Income & Income & Income & Income \\
& R.E. & F.E. & R.E. & F.E. \\
\hline Openness & 0.313 & 0.394 & 0.396 & 0.465 \\
& $(0.083)_{* * *}$ & $(0.094)_{* * *}$ & $(0.075)_{* * *}$ & $(0.086)_{* * *}$ \\
Investment & 1.105 & 0.969 & 1.075 & 0.934 \\
& $(0.254)_{* * *}$ & $(0.256)_{* * *}$ & $(0.258)_{* * *}$ & $(0.256)_{* * *}$ \\
Government Exp. & -0.506 & -0.198 & -0.496 & -0.203 \\
& $(0.271)_{*}$ & $(0.283)$ & $(0.275)_{* *}$ & $(0.283)$ \\
Human & 0.202 & 0.180 & 0.198 & 0.166 \\
& $(0.022)_{* * *}$ & $(0.070)_{* * *}$ & $(0.022)_{* * *}$ & $(0.070)_{* *}$ \\
Natural Resources $\left(\frac{X_{N R}}{Y}\right)$ & 0.471 & 0.398 & & \\
Natural Resources II $\left(\frac{X_{N R}}{T X}\right)$ & $(0.192)_{* *}$ & $(0.209)_{*}$ & & \\
Terms of Trade & & & -0.027 & 0.007 \\
& & & $(0.083)$ & $(0.087)$ \\
R2 within & 0.833 & 0.707 & 0.707 & 0.572 \\
Observations & $(0.326)_{* *}$ & $(0.333)_{* *}$ & $(0.326)_{* *}$ & $(0.324)_{*}$ \\
& 0.39 & 0.39 & 0.39 & 0.40 \\
\hline
\end{tabular}

Standard errors in parentheses; $*$ significant at 10 percent $;_{* *}$ significant at 5 percent; $* * *$ significant at 1 percent. All the random effects regressions are estimated with regional dummies for African and Latin American countries. 
nor the human capital variable is statistically significant beyond the 10 percent level, but the null hypothesis that both coefficients are zero is rejected. In regressions 5.2 and 5.3 only one of the two variables is statistically significant, but again the null hypothesis that both coefficients equal zero is rejected. In regressions 5.1 and 5.2 the coefficient on the interaction term reaches a higher statistical significance than that on human capital alone. For this reason, and given the specification of our model, we estimate a set of equations (regressions 5.4 to 5.7) that include human capital only through the interaction effect with natural resources. In these new specifications both the coefficient on natural resources and that on its interaction term are statistically significant at the 1 percent level in the fixed effects estimations, and at the 5 percent level in the random effects estimations. We also perform the Hausman test to determine whether the random or the fixed effects specification is more appropriate for each measure of natural resources. In both cases we reject the null hypothesis that there is no systematic difference in the coefficients estimated by the two methods.

Given the economic significance of the coefficient on the interaction term, we investigate whether it is possible not only to decrease but also to change the sign of the effect of natural resources on growth. Therefore, based on the coefficient of the interaction term, we solve for the number of years of schooling at which it is possible to recover a net positive effect of natural resources on growth. This is equivalent to recovering from our estimations a threshold value for $H$ such that

$$
\frac{d \gamma_{y}}{d N a t u r a l}=\alpha_{4}-\alpha_{8} \cdot \text { Human } \geq 0
$$

In Table 5 we find that human capital always offsets the negative effects of natural resources on economic growth, and this offsetting effect is increasing in the level of human capital. Moreover, it is possible that this negative effect turns positive for economies with enough human capital. However, the point estimates of the number of years of schooling that fully offset the negative impact of natural resources range from 2.7 (in equation 5.7) to 10.2 years (in equation 5.6). On the one hand, this could imply that natural resources hamper economic growth and that, according to our model, human capital may only partly offset the negative effect of natural resources. On the other hand, the most optimistic view would conclude that the effect of natural resources on growth is positive, given the low level of human capital needed to outweigh the negative impact of natural resources. The truth most likely 


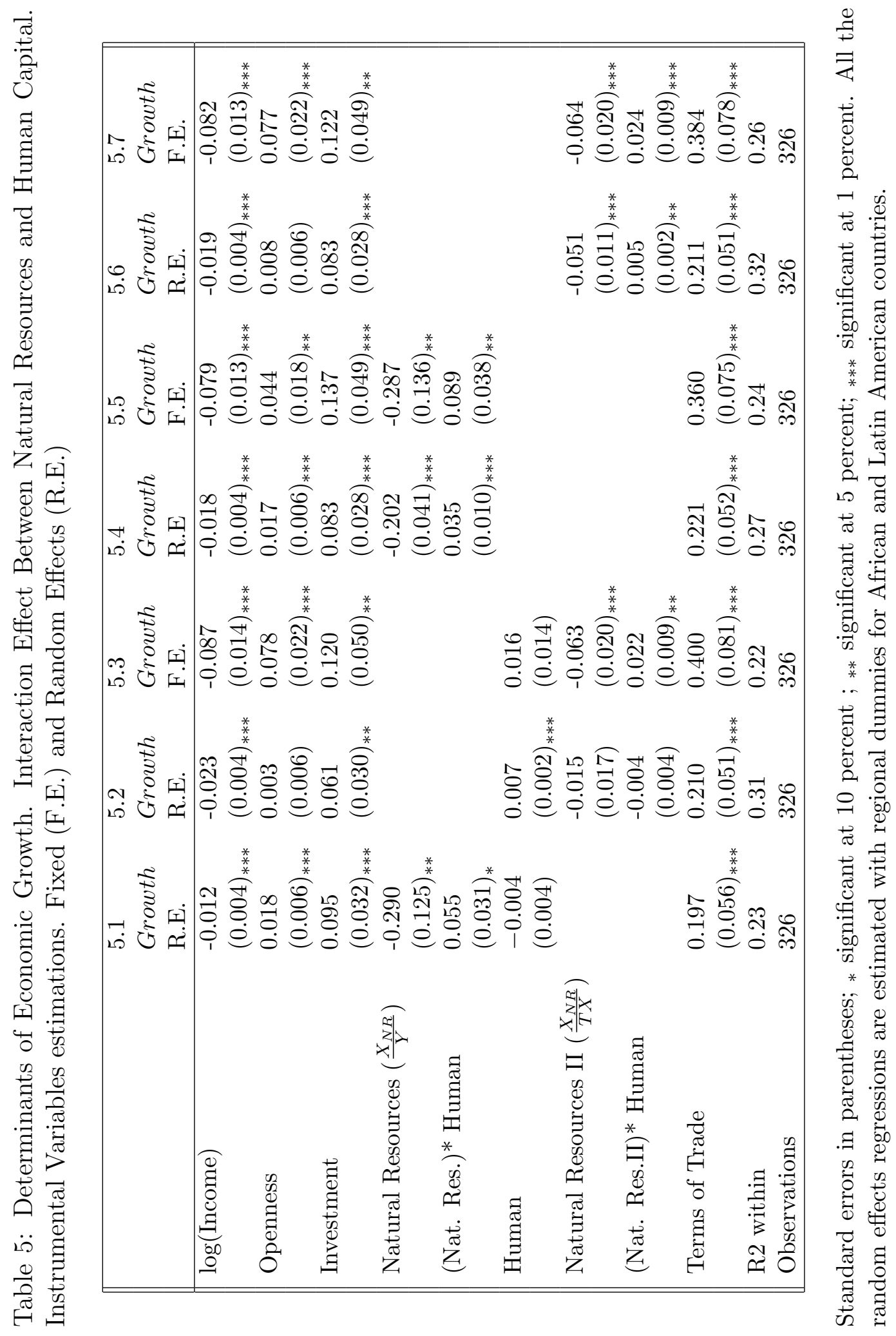


lies between these two positions. Thus it would be correct to argue that natural resources could hamper growth in countries with low levels of human capital, but that in economies with an abundance of human capital, natural resources could propel growth.

Taking the average of the coefficients estimated in equations 5.4 to 5.7 suggests that 5.5 years of schooling is the minimum required for natural resources to have a net positive effect on growth.

Table 6 lists those countries for which data are available for the full sample period whose level of human capital is above the threshold (5.5 years) at which natural resources begin to exert a positive effect on growth. Table 6 also shows, at five-year intervals, natural resources exports as a fraction of these countries' GDP $\left(\frac{X_{N R}}{Y}\right)$ and of their total exports $\left(\frac{X_{N R}}{T X}\right)$. Especially interesting are those countries (indicated by asterisks) whose natural resources exports by these measures are above the sample average.

Perhaps the most striking observation to be made in Table 6 is that some countries that known to be richly endowed with natural resources nevertheless have a small share of exports of primary products in GDP . Among these are Australia, Canada, Denmark, Finland, New Zealand, Norway, Sweden, and the United States. Wright (1990) argues that, over the period 1880-1920, the distinctive characteristic of U.S. exports was their intensity in nonrenewable natural resources. Nevertheless, for the period 1879-99, he finds that net manufacturing exports depend negatively on natural resources, whereas for the period 1909-40 this relationship is reversed. Can human capital accumulation explain this process? Our evidence supports such a hypothesis. Certainly, whether the same history applies to some of the countries in Table 6, and if so, to which ones, is a question that deserves a closer look and which we will explore in future research.

In short, the evidence seems to indicate that natural resources are a hindrance to economic growth in countries with low levels of human capital. Our model predicts that this effect comes about because the natural resources sector draws resources from other economic sectors that could generate further economic growth. However, as the country's development continues, the accumulation of human capital may eliminate this effect. Hence the impact of natural resources could be offset through the accumulation of human capital. 


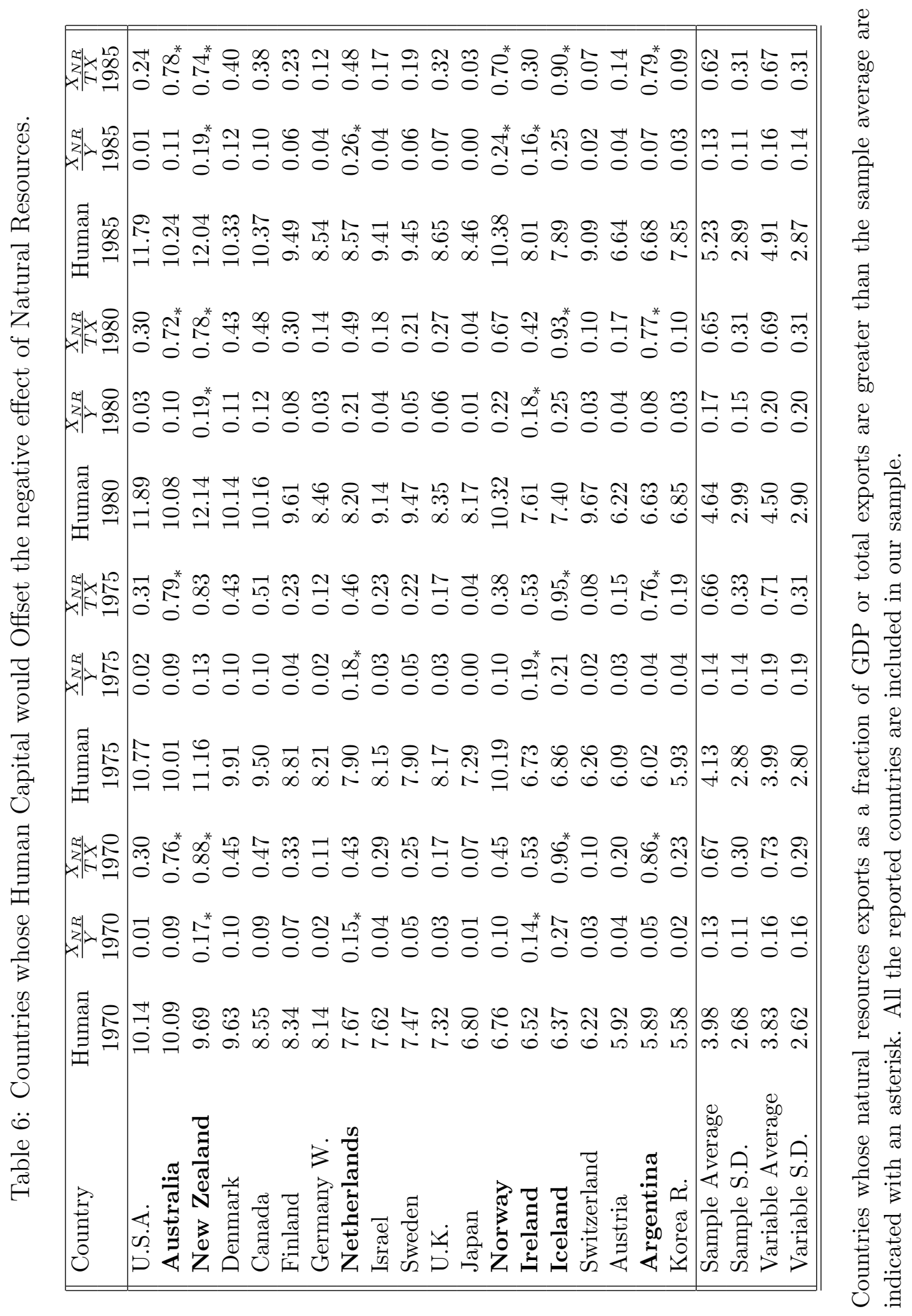




\section{Conclusion}

We have found an inverse relationship between a country's rate of economic growth and the relative abundance of its natural resources, and a positive relationship between level of income and natural resources. These findings agree with the main predictions of our model. Moreover, in contrast to other empirical work, we find statistical evidence of a positive relationship between human capital and economic growth after controlling for natural resource abundance. ${ }^{19}$ Based on the model's predictions, we have also extended the usual specifications of economic growth regressions by incorporating a term that interacts human capital and natural resources. This allows us to derive a list of countries that, today or in the past, have been relatively rich in natural resources and human capital, and whose levels of human capital more than offset the expected negative effect of natural resource abundance on growth.

The results indicate that natural resources reduce economic growth in countries with low levels of human capital, although there is a positive income effect. The negative effects on growth arise as the natural resources sector draws economic resources from other sectors that would otherwise be capable of generating further economic growth. Our model and the evidence we have presented show that the main resource that is siphoned off from these growth-enhancing activities is human capital. If human capital is abundant, however, this effect may be minimized.

Indeed, our evidence strongly suggests that abundant human capital not only partially compensates for the negative effects of abundant natural resources on economic growth, as implied by our model, but may actually more than offset it. In our model a high level of human capital diminishes the growth-reducing effect of the reallocation of resources from a dynamic sector, such as industry, to the exploitation of natural resources. Further work is needed to fully account for this evidence. It may be possible, in a multisector model with close interlinkages between natural resources and industrial activities, to formalize the idea of the joint development of an industrial or high-technology sector simultaneously with natural resources, if the economy is rich in human capital. This is what may have happened in Scandinavia, wherethe development of natural resources was accompanied by growth of an industrial base linked to the natural resources sector, for example in forestry (wood and pulp processing).

\footnotetext{
${ }^{19}$ See Sachs and Warner (1995), Gylfason et al. (1999), and Asea and Lahiri (1999).
} 
For such a synergy to occur, however, the country must be well endowed with human capital.

The aggregate data, as well as our review of the Scandinavian experience since the late nineteenth century, provide supporting evidence for our model. In addition, we have shown that abundance of natural resources leads to higher income, so that one cannot infer from the growth effects alone what the welfare implications of being rich in natural resources might ultimately be. Indeed, from the perspective of our model, increased natural resources imply higher current and future income, so that welfare increases when natural resources become more abundant. A country would not benefit from giving away its natural resource endowment, as one might mistakenly conclude from models that emphasize only the growth effect.

As this paper has shown, a country that is rich in natural resources can start with a high level of income, accumulate human capital, and see its growth accelerate. In this sense, natural resources need not be a curse. However, extremely low levels of human capital may cause such an economy to stagnate, because it then tends to specialize in natural resources extraction.

\section{References}

Asea, Patrick and Amartya Lahiri, "The Precious Bane," Journal of Economic Dynamic and Control, April 1999, 23 (5-6), 823-49.

Barro, Robert and Xavier Sala i Martin, Economic Growth, Mc Graw Hill, 1995.

_ _ Gregory Mankiw, and Xavier Sala i Martin, "Capital Mobility in Neoclassical Models of Economic Growth," American Economic Review, 1995, 85 (1), 103115.

Benavot, Aaron and Phyllis Riddle, "The Expansion of Primary Education, 18701940: Trends and Issues," Sociology of Education, July 1988, pp. 191-210.

Blomstrom, Magnus and Patricio Meller, eds, Trayectorias Divergentes. Comparación de un siglo de desarrollo económico Latinoamericano y Escandinavo, CieplanHachette, 1990. Santiago. 
Boughton, James, "Commodity and Manufactures Prices in the Long Run," May 1991. International Monetary Found Working Paper, 91/47,.

Bravo-Ortega, Claudio, "Does Geography Matters for the Big Push. Why Scandinavia and not Latin America?," 1999. Mimeo Berkeley.

Caselli, Francesco, Gerald Esquivel, and Lefort Fernando, "Reopening the Convergence Debate: A new Look at Cross Country Growth Empirics," Journal of Economic Growth, 1996, 1 (3), 363-89.

Chenery, Hollis B. and Moche Syrquin, Patterns of Development. 1950-1970, London: Oxford University Press, 1975.

Davis, Graham, "Learning to Love the Dutch Disease: Evidence from the Mineral Economies," World Development, 1995, 23 (10), 1765-79.

Easterly, William, Pritchett Kremer, Michael Lant, and Lawrence Summers, "Good Policy or Good Luck? Country Growth Performance and Temporary Shocks," Journal of Monetary Economics, December 1993, 32 (3), 459-83.

Edwards, Sebastian, "Openness, Productivity and Growth: What do we really know?," March 1997. National Bureau of Economic Research (Cambridge, MA) Working Paper No 5978.

Farzin, Y.H, "Optimal saving policy for exhaustible resource economies," Journal of Development Economics, February 1999, 58 (1), 149-84.

Feenstra, Robert, Dorsati Madani, Tzu-Han Yang, and Chi-Yuan Liang, "Testing Endogenous Growth in South Korea and Taiwan," May 1997. National Bureau of Economic Research (Cambridge, MA) Working Paper No. 6028.

Gylfason, Thorvaldur, "Natural resources, Education and Economic Development," European Economic Review, May 2001, 45 (4-6), 847-59. and Gylfi Zoega, "Natural Resources and Economic Growth: The Role of Investment," January 2002. Paper presented at the Central Bank of Chile and World Bank Conference on Economic Growth and Natural Resources. Santiago, Chile. 
_ _ Thor Herbertsson, and Gylfi Zoega, "A Mixed Blessing: Natural Resources and Economic Growth," Macroeconomic Dynamics, 1999, 3 (2), 204-25.

Heckscher, Eli, An Economic History of Sweden, Cambridge, MA: Harvard University Press, 1968.

Krueger, Alan and Mikael Lindahl, "Education for Growth: Why and For Whom?," February 1999. Mimeo Princeton University.

Krugman, Paul, Rethinking International Trade, Cambridge, MA. MIT Press, 1990.

Lane, Philip and Aaron Tornell, "Power, Growth, and the Voracity Effect," Journal of Economic Growth, June 1996, 1 (2), 213-41.

Leamer, Edward, "Can FTAA Suspend the Law of Gravity and Give Americas High Growth and Better Income Distributions?," March 2003. UCLA Draft.

Lederman, Daniel and William Maloney, "Trade Structure and Growth," September 2002. World Bank, Draft.

Lucas Jr., Robert, "On the Mechanics of Economic Development," Journal of Monetary Economics, July 1988, 22 (1), 3-42.

Maddison, Angus, Monitoring the World Economy 1820-1992, Paris: OECD, 1995.

Maloney, William F., "Innovation and Growth in Resource Rich Countries," Economia, January 2002, 3 (1), 111-168.

Manzano, Osmel and Roberto Rigobon, "Resorce Curse or Debt Overhang," July 2001. NBER Working Paper No. 8390.

Matsuyama, Kiminori, "Agricultural Productivity, Comparative Advantage, and Economic Growth," Journal of Economic Theory, December 1992, 58 (2), 31734.

Michel, Phillipe, "On the Transversality Condition in Infinite Horizon Optimal Problems," Econometrica, July 1982, 50 (4), 975-86. 
Mitchell, B.R., International Historical Statistics: Americas 1750-1993, New York: Stockton Press, 1998.

International Historical Statistics: Europe 1750-1993, New York: Stockton Press, 1998.

Mundlak, Yair, Agriculture and Economic growth. Theory and Measurement., Harvard University Press., 2001.

Murphy, Kevin, Andrei Shleifer, and Robert Vishny, "Industrialization and the Big Push," Journal of Political Economy, 1989, 97 (5), 1003-26.

Neary, Peter and Sweder Van Wijnbergen, Natural Resources and the Macroeconomy, Cambridge, Mass.: The MIT Press, 1986.

O'Rourke, Kevin and Jeffrey Williamson, "Education, Globalization and Catch up: Scandinavia in the Swedish mirror," Scandinavian Economic History Review, 1995, 43 (3), 287-309.

Rodriguez, Francisco and Jeffrey Sachs, "Why do resource abundant Economies Grow More Slowly?," Journal of Economic Growth, September 1999, 4 (3), 277-303.

Romer, Paul, "Increasing Returns and Long Run Growth," Journal of Political Economy, October 1986, 94 (5), 1002-37.

Sachs, Jeffrey and Andrew Warner, "Natural Resource Abundance and Economic Growth," December 1995. NBER Working Paper No. 5398.

__ and __ " "The Big Push, Natural resources Booms and Economic Growth.," Journal of Development Economics, 1999, 59 (1), 47-76.

_ and _ _ "The Curse of Natural Resources," European Economic Review, May 2001, 45 (4-6), 827-38.

Solow, Robert, "Intergenerational Equity and Exhaustible Resources," Review of Economic Studies, Symposium, 1974, pp. 29-45.

Stijns, Jean Philippe, "Natural Resource Abundance and Human Capital Accumulation," June 2001. Mimeo, UC Berkeley. 
Temple, Johnathan, "The New Growth Evidence," Journal of Economic Literature, March 1999, 37 (1), 112-56.

Vincent, Jeffrey, "Resource depletion and economic sustaintability in Malaysia," Enviroment and Development Economics, 1997, 2 (1), 19-37.

Wright, Gavin, "The Origins of American Industrial Success, 1879-1940," The American Economic Review, September 1990, 80 (4), 651-68. 


\section{Appendix A}

\section{Model Derivation and Proofs of Propositions}

The Hamiltonian of the problem in equation 3 (3) can be expressed as follows:

$$
J=u(c) \cdot e^{-\beta t}+\lambda \cdot e^{-\beta t}\left(a \cdot H_{I}+p_{1} \cdot R \cdot H_{R}^{\delta}-p_{2} \cdot c\right)+\tau_{2} \cdot e^{-\beta t}\left(H_{I}+H_{R}-1 \cdot H\right)
$$

The first-order conditions of the problem are given by

$$
\begin{gathered}
\frac{d J}{d c_{t}}=0 \Leftrightarrow u^{\prime}(c) e^{-\beta t}=p_{2} \cdot \lambda e^{-\beta t} \\
\frac{d J}{d H_{I}}=0 \Leftrightarrow \lambda \cdot e^{-\beta t} \cdot a+e^{-\beta t} \cdot \tau_{2}=0 \\
\frac{d J}{d H_{R}}=0 \Leftrightarrow \lambda \cdot e^{-\beta t} p_{1} \cdot R \cdot \delta \cdot H_{R}^{\delta-1}+e^{-\beta t} \cdot \tau_{2}=0 \\
\frac{d J}{d H}=-\dot{\lambda}+\lambda \beta=-\tau_{2} \Rightarrow \frac{-\dot{\lambda}}{\lambda}+\beta=-\frac{\tau_{2}}{\lambda} \Rightarrow \frac{-\dot{\lambda}}{\lambda}=a-\beta
\end{gathered}
$$

Hence we can express the return to human capital accumulation as follows:

$$
r_{H}=-\frac{\tau_{2}}{\lambda}=a=p_{1} \cdot \delta \cdot R \cdot H_{R}^{\delta-1}
$$

From the previous expression we can note that $H_{R}$ is constant over time. We will explore further the implicances of this fact in proposition 2 .

Finally, we can verify that the system satisfies Michel's transversality condition ${ }^{20}$

\footnotetext{
${ }^{20}$ See Michel (1982).
} 
$\lim _{t \rightarrow \infty} J(t)=0$ as long as $a<\beta(1+\sigma)$

\section{Proof. Proposition 1}

Taking the log and differentiating equation (8), we get

$$
\frac{\dot{c}}{c}=\frac{1}{\sigma}(a-\beta)
$$

Note that the rate of growth of consumption is constant at any moment in time and depends on the technology utilized in the industrial sector.

Now we derive the steady-state growth rates for each variable. Dividing the budget constraint by the average level of human capital, $H$, and rearranging:

$$
\frac{\dot{H}}{H}=a-\frac{a}{H} \cdot H_{R}+p_{1} \cdot \frac{H_{R}^{\delta}}{H}-\frac{p_{2} \cdot c}{H}
$$

Imposing the fact that in the steady state the rates of variation of human capital and consumption are constant, noting that $H_{R}$ is constant and taking the derivative with respect to time, we get

$$
0=\frac{\dot{H}}{H^{2}} \cdot H_{R}-p_{1} \cdot \frac{H_{R}^{\delta}}{H} \frac{\dot{H}}{H}-p_{2}\left(\frac{\dot{c}}{c} \frac{c}{H}-\frac{\dot{H}}{H} \frac{c}{H}\right)
$$

Multiplying by $H$ and again taking the derivative with respect to time implies

$$
0=-\left(\frac{\dot{c}}{c}-\frac{\dot{H}}{H}\right) \dot{c}
$$

Then, in the steady state, human capital and consumption will grow at the same rate. The amount of human capital in the natural resources sector will be constant, 
whereas that of human capital in the industrial sector will grow at the same rate as total human capital. Consequently the "reduced" product will also grow at the same rate. It is important to note that the evolution of the variables in the steady state does not depend on the relative abundance of natural resources, and that the growth rate of the economy depends only on the productivity of the sector subject to externalities.

\section{Proof. Proposition 2}

The first-order conditions have some interesting implications with respect to the evolution of the productive structure of the economy. To analyze these, we first solve $H_{R}$, which can be expressed as follows:

$$
H_{R}=\left(\frac{p_{1} \cdot R \cdot \delta}{a}\right)^{\frac{1}{1-\delta}}=\text { constant }=L_{R} \cdot H
$$

where $L_{R}$ is the fraction of the labor force in the natural resources sector. Note that the fraction of human capital employed in the natural resources sector is inversely proportional to the level of human capital per capita, $H$. Consistent with this, the industrial sector will produce output using a share $L_{I}$ of the labor force, which will increase with $H$. Indeed,

$$
L_{I}=1-L_{R}=1-\frac{1}{H}\left(\frac{p_{1} \cdot R \cdot \delta}{a}\right)^{\frac{1}{1-\delta}}
$$

At the same time, the output of the natural resources sector is constant, and as long as human capital is increasing, the fraction of total output belonging to this sector will decrease over time. 
Proof. Proposition 3

Differentiating total output yields

$$
\begin{aligned}
\frac{d}{d R}\left(Y_{0}\right)=\frac{d}{d R} & {\left[a \cdot\left(H-H_{R}(R)\right)+p_{1} \cdot R \cdot H_{R}^{\delta}(R)\right]=} \\
& =-a \cdot \frac{\partial}{\partial R} H_{R}(R)+p_{1} \cdot H_{R}^{\delta}(R)+p_{1} \cdot R \cdot \delta \cdot H_{R}^{\delta-1}(R) \cdot \frac{\partial}{\partial R} H_{R}(R)
\end{aligned}
$$

Rearranging the equilibrium conditions for the allocation of labor in the productive sectors as $p_{1} \cdot R \cdot \delta \cdot H_{R}^{\delta-1}(R)-a=0$, and substituting in equation (18), it can be shown that

$$
\frac{d}{d R}\left(Y_{0}\right)=p_{1} \cdot H_{R}^{\delta}(R)>0
$$

\section{Transitional dynamics}

This analysis closely follows Barro and Sala-i-Martin (1995). Define $\psi=\frac{Y}{H_{i}}$, and $\chi=\frac{C}{H i}$

Then $\dot{\psi}=\frac{d}{d t}\left(\frac{Y}{H_{i}}\right)=\frac{d}{d t}\left(a+\frac{p_{1} R H_{R}^{1-\delta}}{H_{i}}\right)=\frac{d}{d t}\left(a+\frac{B}{H_{i}}\right)=-\frac{B}{H_{i}} \frac{\dot{H}_{i}}{H_{i}}$

and

$$
\dot{\psi}=(a-\psi) \frac{\dot{H}_{i}}{H_{i}}
$$

Noting that $\frac{\dot{H}_{i}}{H_{i}}=\frac{\dot{H}}{H-H_{R}}=\frac{\dot{H}}{H_{i}}=\psi-\chi$, we can express equation (20) as:

$\dot{\psi}=(a-\psi) \cdot(\psi-\chi)$ 
Differentiating $\chi$ respect to time yields

$\dot{\chi}+\chi \cdot \frac{\dot{H}_{i}}{H_{i}}=\frac{\dot{C}}{H_{I}}$, replacing in the growth rate of consumption implies

$\frac{\dot{C}}{H_{I}}=\frac{C}{\sigma H_{I}}(a-\beta)=\frac{\chi}{\sigma}(a-\beta)$

$\dot{\chi}+\chi \cdot(\psi-\chi)=\frac{\chi}{\sigma}(a-\beta)$

Hence the system evolves according to the following two differential equations:

$$
\begin{gathered}
\dot{\psi}=(a-\psi) \cdot(\psi-\chi) \\
\dot{\chi}=\frac{\chi}{\sigma}(a-\beta)-\chi \cdot(\psi-\chi)
\end{gathered}
$$

From proposition 1 we know that, in the steady state, all the variables grow at the same rate. Therefore $\dot{\psi}=\dot{\chi}=0$, which replaced in equations (21) and (22) allow us to find the steady-state values for each of our variables. These are then determined by

$$
\begin{gathered}
\left(a-\psi_{s s}\right) \cdot\left(\psi_{s s}-\chi_{s s}\right)=0 \\
\chi_{s s}\left(\frac{a-\beta}{\sigma}-\psi_{s s}+\chi_{s s}\right)=0
\end{gathered}
$$

Then the system has three steady states: two for consumption equal to zero, and one for positive consumption. Indeed, the solutions to the equations (23) and (24) are

$$
\{\psi=0, \chi=0\},\{\chi=0, \psi=a\},\left\{\chi=\frac{-a+\beta+\sigma a}{\sigma}, \psi=a\right\}
$$


Linearizing the system of equations (21), and (22) around the steady states, we get

$$
\left[\begin{array}{c}
\dot{\psi} \\
\dot{\chi}
\end{array}\right]=\left[\begin{array}{cc}
a-2 \cdot \psi_{s s}+\chi_{s s} & -\left(a-\psi_{s s}\right) \\
-\chi_{s s} & \frac{1}{\sigma}(a-\beta)+2 \cdot \chi_{s s}-\psi_{s s}
\end{array}\right]\left[\begin{array}{c}
\psi-\psi_{s s} \\
\chi-\chi_{s s}
\end{array}\right]
$$

Around the steady state $\left\{\psi_{s s}=0, \chi_{s s}=0\right\}$ the system is completely unstable. When the equilibrium is $\left\{\chi_{s s}=0, \psi_{s s}=a\right\}$ the system is completely stable, whereas for the third equilibrium, $\left\{\chi_{s s}=\frac{-a+\beta+\sigma a}{\sigma}, \psi_{s s}=a\right\}$, the system has a saddle path as long as $(-a+\beta)<0$ and $\frac{1}{\sigma}(a-\beta)+2 \cdot \frac{-a+\beta+\sigma a}{\sigma}-a=\frac{-a+\beta+\sigma a}{\sigma}>0$, which seems to be a plausible assumption given standard values for the parameters of the model.

However, noting that the minimum possible value for $\psi$ is $a$, the equilibria $\{\psi=0, \chi=0\}$ is unfeasible. Given that the second equilibrium is fully stable, we will analyze the dynamic around the third, unstable equilibrium.

In this third equilibrium the linearized system is $\left[\begin{array}{l}\dot{\psi} \\ \dot{\chi}\end{array}\right]=\left[\begin{array}{cc}-\frac{1}{\sigma}(a-\beta) & 0 \\ -\frac{-a+\beta+\sigma a}{\sigma} & \frac{-a+\beta+\sigma a}{\sigma}\end{array}\right]\left[\begin{array}{c}\psi-a \\ \chi-\frac{-a+\beta+\sigma a}{\sigma}\end{array}\right]$

The solution for the system is the following:

$$
\chi=\chi_{s s}+\left(\chi_{0}-\chi_{s s}\right) \cdot e^{-\frac{1}{\sigma}(a-\beta) \cdot t}
$$


$\psi-\psi_{s s}=-\left(\chi-\chi_{s s}\right) \cdot\left(\frac{\frac{-a+\beta+\sigma a}{\sigma}-{ }^{-\frac{1}{\sigma}(a-\beta)}}{-\frac{-a+\beta+\sigma a}{\sigma}}\right)=\left(\chi-\chi_{s s}\right) \cdot\left(\frac{a}{\frac{-a+\beta+\sigma a}{\sigma}}\right)=\left(\chi-\chi_{s s}\right) \cdot\left(\frac{\psi_{s s}}{\chi_{s s}}\right)$

Figure 1 shows the dynamic under the assumptions needed for having the third equilibrium with a saddle path.

Now we derive the growth rate for income per capita, expressing it as a function of the variables used in linearizing the system. Thus we obtain

$$
\gamma_{y}=\gamma_{\psi}+\gamma_{h i}
$$

From the original system of equations we have

$\gamma_{\psi}=\gamma_{h i} \cdot\left(\frac{a}{\psi}-1\right)=\gamma_{h i} \cdot\left(\frac{\psi_{s s}}{\psi}-1\right)$

Thus, replacing in equation (28)

$\gamma_{y}=\gamma_{\psi} \cdot\left(1+\left(\frac{\psi}{\psi_{s s}-\psi}\right)\right)=\gamma_{\psi} \cdot\left(\frac{\psi_{s s}}{\psi_{s s}-\psi}\right)$

Recalling the solution for the linearized system we obtain

$\gamma_{\psi}=-\left(\frac{\psi_{s s}}{\chi_{s s}}\right) \cdot \frac{\left(\chi_{0}-\chi_{s s}\right) \cdot \gamma_{s s} e^{-\gamma_{s s} \cdot t}}{\psi}$

Therefore, we can express the rate of growth of output as

$\gamma_{y}=-\left(\frac{\psi_{s s}}{\chi_{s s}}\right) \cdot \frac{\left(\chi_{0}-\chi_{s s}\right) \cdot \gamma_{s s} e^{-\gamma_{s s} \cdot t}}{\psi} \cdot\left(1+\left(\frac{\psi}{\psi_{s s}-\psi}\right)\right)$

Using equation (26) and equation (27) this can be reduced to

$$
\gamma_{y}=\left(\frac{\psi_{s s}}{\psi}\right) \cdot \gamma_{s s}=\frac{H_{i}}{Y} \cdot \psi_{s s} \cdot \gamma_{s s}
$$


After some algebra, and recalling the fact that $\psi_{s s}=a$ and that $\gamma_{s s}$ is the steadystate growth rate, we can rewrite equation (29) as follows:

$$
\gamma_{y}=\frac{a \cdot H_{i}}{Y} \cdot \gamma_{s s}=\left(1-X_{n r}\right) \cdot \gamma_{s s}=\gamma_{s s}-\gamma_{s s} \cdot X_{n r}
$$

Hence we have derived the inclusion of natural resources exports as a fraction of GDP (or of total exports) as an explanatory variable. This may be considered an extension of previous empirical specifications existing in the literature.

Thus, to prove proposition 4, we can differentiate equation (29).

\section{Proof. Result 1}

From proposition 3 we have

$$
\frac{d}{d R}\left(Y_{0}\right)=p_{1} \cdot H_{R}^{\delta}(R)>0
$$

Now we can express human capital allocated to the industrial sector as a function of total human capital and the specific factors. This is: $H_{i}=H-H_{R}=H-\left(\frac{a}{p \cdot R \cdot \delta}\right)^{\frac{1}{\delta-1}}$

Therefore we can express the total derivative of the growth rate with respect to the specific factor in the natural resources sector as follows:

$$
\frac{d}{d R}\left(\gamma_{y}(R, H, Z)\right)=K_{0} \cdot \frac{d}{d R}\left(\frac{H_{i}}{Y}\right)=\frac{\frac{\partial}{\partial R}\left(H_{i}\right) Y-H_{i} \frac{\partial}{\partial R}(Y)}{Y^{2}}
$$

Noting that $\frac{\partial}{\partial R}\left(H_{i}\right)<0$ and $\frac{\partial}{\partial R}(Y)>0$, we proved that $\frac{d}{d R}\left(\gamma_{y}(R, H, Z)\right)<0$ 
Now, after some manipulation of $\frac{d}{d R}\left(\gamma_{y}(R, H, Z)\right)$, we can derive $\frac{d^{2}}{d h d R}\left(\gamma_{y}(R, H, Z)\right)$, which can be rewritten as

$$
\frac{d^{2}}{d H d R}\left(\gamma_{y}(R, H, Z)\right)=\left(p_{1} \cdot H_{R}^{\delta} \cdot\left(2 \cdot \frac{Y_{I}}{Y_{\text {Total }}}-1\right)+a \cdot \frac{H_{R}}{R}\left(\frac{1}{1-\delta}\right)\right) \frac{1}{Y^{2}}
$$

If $R$ is big enough, the fraction of production in the industrial sector is small (the same can be argued for low levels of human capital) and the first term becomes negative. On the other hand, for any value of $R$ there exists a level of human capital such that equation (33) is positive, because the fraction of GDP belonging to the industrial sector is an increasing function of the level of human capital accumulation. Whether the total effect is negative will depend on the parameters. What is guaranteed is the existence of $H^{*}>0$, such that $\forall H>H^{*}$ the cross differentiation is positive.

\section{Natural Resources and zero growth}

In this section we assume that, given the productivity of each of the two sectors, and given the initial level of human capital, the economy will produce in the natural resources sector only. For that we need to impose that given the population in the economy, the marginal productivity of human capital in the natural resources sector is greater than $a$, which implies $\left(\frac{p_{1} \cdot R \cdot \delta}{a}\right)^{\frac{1}{1-\delta}}>H_{0}$. We also assume that $\beta>a$. 
Note that the first condition simply implies a relative abundance of natural resources with respect to the factor specific to the industrial sector. Hence there may be cases where this relative abundance can induce greater welfare even in the absence of growth, when compared with the alternative of nonproduction in the natural resources sector but a positive growth rate.

Thus the problem is reduced to a simplified version of the Ramsey model:

$$
\begin{aligned}
& \operatorname{Max} \int_{0}^{\infty} \frac{c_{t}^{(1-\sigma)}-1}{(1-\sigma)} \cdot e^{-\beta t} d t \\
& \text { st } \\
& \dot{H}=p_{1} R H_{R}^{\delta}-C_{t}
\end{aligned}
$$

After redefining constants and variables in per capita terms, the problem reduces to imposing first-order conditions over the following Hamiltonian:

$$
\begin{aligned}
& J=u(C t) \cdot e^{-\beta t}+\lambda \cdot e^{-\beta t}\left(p R H^{\delta}-c_{t}\right) \\
& \frac{d J}{d c_{t}}=0 \Leftrightarrow u^{\prime}\left(c_{t}\right) e^{-\beta t}=\lambda \\
& \frac{d J}{d H}=-\dot{\lambda}+\lambda \beta=\lambda p_{1} \delta R H^{\delta-1} \Rightarrow \frac{-\dot{\lambda}}{\lambda}+\beta=p_{1} \delta R H^{\delta-1}
\end{aligned}
$$

Proof. Proposition 4

Taking the logarithm and differentiating $\frac{d J}{d C}=0$, we get

$$
\frac{\dot{c}}{c}=\frac{1}{\sigma}\left(p_{1} \delta R H^{\delta-1}-\beta\right)
$$

As usual, in the steady state the economy grows at a rate of zero, because the firm utilizes human capital up to the point at which decreasing returns to human 
capital equal the discount rate of the representative agent. Consequently, there is no incentive for human capital accumulation. If there is more human capital than can be utilized in the natural resources sector, there may even be a deaccumulation of human capital.

To analyze the steady-state growth rates, we divide by $H$ and differentiate the budget constraint, getting $\frac{d}{d t} \frac{\dot{H}}{H}=\frac{d}{d t} p_{1} \delta R H^{\delta-1}-\frac{d}{d t} \frac{C_{t}}{H}$

$0=0-\frac{C_{t}}{H}\left(\gamma_{c}-\gamma_{H}\right)$

Thus, we have

$$
\gamma_{c}=\gamma_{H}=0
$$




\section{Appendix B: Data}

Penn World Tables, version 5.6: Real GDP per capita in constant dollars, base 1985 (RGDPCH), Real investment share of GDP (I), Real government share of GDP (G), Openness (Exports+Imports)/GDP (OPEN)

Barro and Lee Database, 1994.: Average years of schooling in the total population over age 25 (HUMAN), Average years of schooling in the male population over age 25 (HUMAN (MALE)), Average years of secondary schooling in the total population over age 25 (SYR)

World Tables CD Rom, 1993-1996. The following variables

Exports of Fuel: Comprise commodities in SITC Revision 1, Section 3 (mineral fuels and lubricants and related materials); (TX VAL FUEL CD)

Exports of Non Fuel Primary Products: commodities in SITC Revision 1, Sections 0,1,2,4, and Division 68 (food and live animals, beverages and tobacco, inedible crude materials, oils, fats, waxes, and nonferrous metals); (TX VAL NFPP CD).

Exports of Metals and Minerals: Exports of metals and minerals comprise commodities in SITC Revision 1, Sections 27 (crude fertilizer, minerals nes), 28 (metalliferous ores, scrap) and 68 (nonferrous metals); (TX VAL METM CD).

GDP at Market Prices: Measures the total output of goods and services for final 
use occurring within the domestic territory of a given country, regardless of the allocation to domestic and foreign claims. Gross domestic product at purchaser values (market prices) is the sum of GDP at factor cost and indirect taxes less subsidies. Data are expressed in current U.S. dollars.

The figures for GDP are dollar values converted from domestic currencies using single-year official exchange rates. For a few countries where the official exchange rate does not reflect the rate effectively applied to actual foreign transactions, an alternative conversion factor is used.

Merchandise Exports: refer to all movable goods (excluding nonmonetary gold) involved in a change of ownership from residents to nonresidents. Merchandise exports are valued free on board (f.o.b) at the customs frontier and include the value of the goods, the value of outside packaging, and related distributive services used up to, and including, loading the goods onto the carrier at the customs frontier of the exporting country. (TX VAL MRCH CD)

The primary source is the UNCTAD database supplemented with data from the UN COMTRADE database, IMF's International Financial Statistics, and national and other sources. Because of the source Change, the data for some countries may differ significantly from those presented last year. Also, export and import component values may not sum to the total shown.

Merchandise Imports: Merchandise imports refer to all movable goods (exclud- 
ing nonmonetary gold) involved in a change of ownership from nonresidents to residents. Merchandise imports are valued at their c.i.f. (cost, insurance and freight) price. In principle, this price is equal to the f.o.b. transaction price plus the costs of freight and merchandise insurance involved in shipping goods beyond the f.o.b. point. Data are in current U.S. dollars.

The primary source is the UNCTAD database supplemented with data from the UN COMTRADE database, IMF's International Financial Statistics, and national and other sources. Because of the source Change, the data for some countries may differ significantly from those presented last year. Also, export and import component values may not sum to the total shown.(TM VAL MRCH CD).

All the previous variables are expressed in current U.S.\$ dollars.

Merchandise Export Price Index: This item is a price index measuring changes in the aggregate price level of a country's merchandise exports f.o.b. over time.(TX PRI MRCH XD).

Merchandise Import Price Index: This item is a price index measuring changes in the aggregate price level of a country's merchandise imports c.i.f. over time.(TM PRI MRCH XD). 
Figure 2: Growth and Natural Resource Abundance

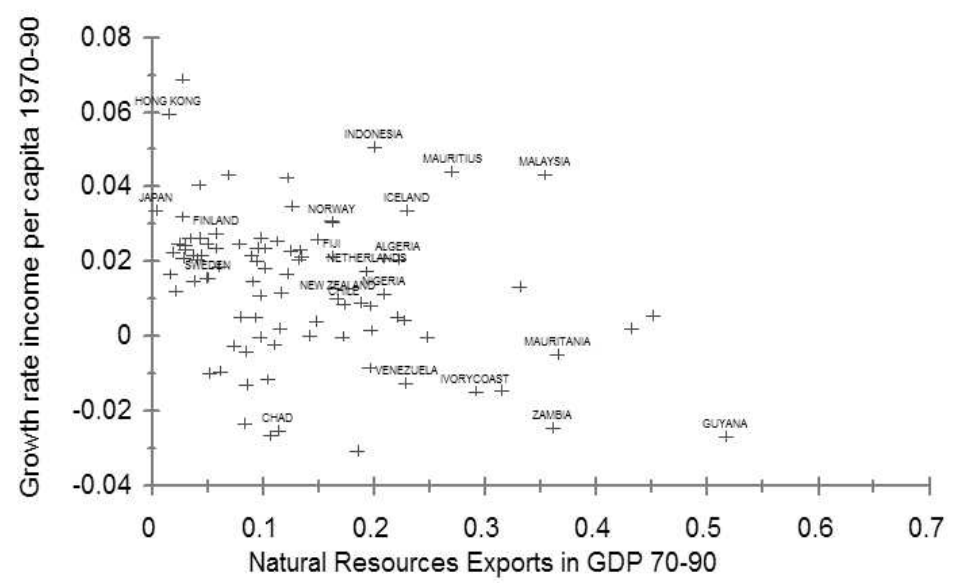

Figure 3: Income and Natural Resource Abundance.

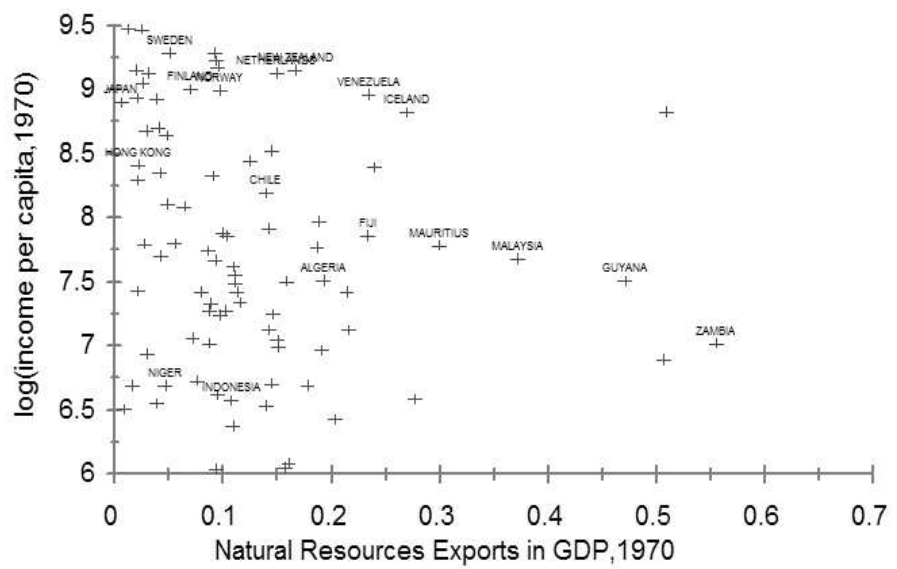


Figure 4: Phase diagram.

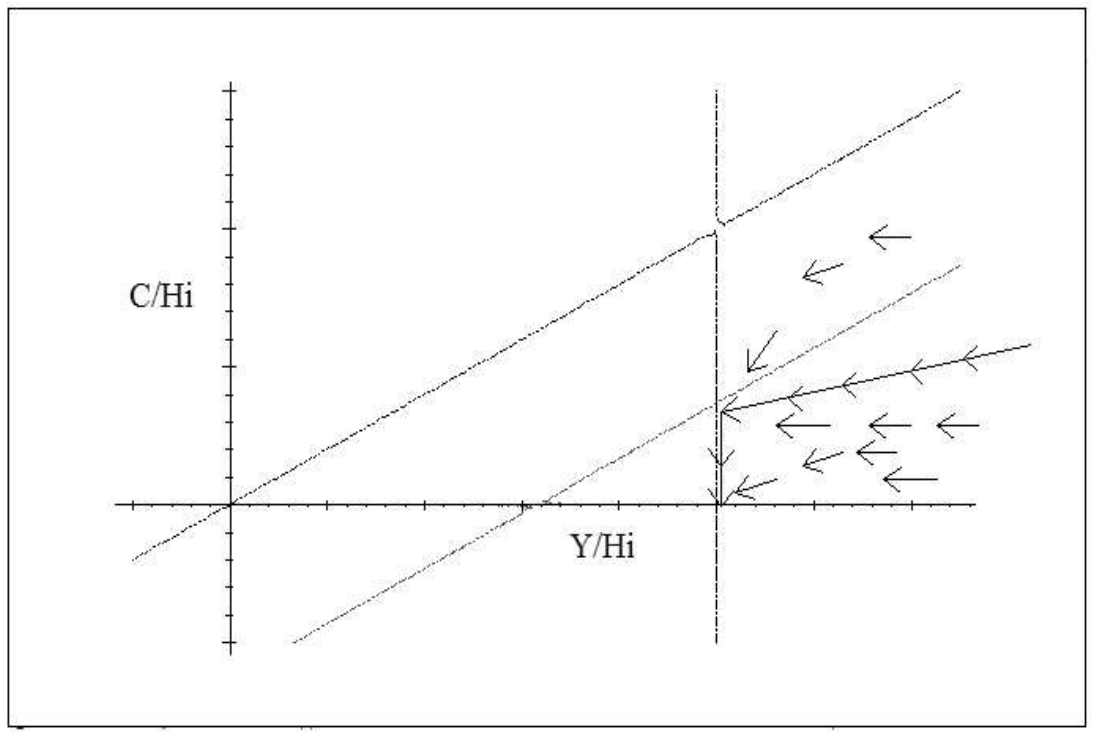

